\title{
Evaluation of the Babies at Risk Surveillance System in Rushinga District, Mashonaland Central Province, Zimbabwe, 2015
}

\author{
Alice Kudzaishe Dzvukamanja1, Cremance Tshuma², Donewell Bangure1, More Mungati1 ${ }^{1}$, Tsitsi \\ Juru $^{1 *}$, Notion Tafara Gombe ${ }^{1}$, Mufuta Tshimanga ${ }^{1}$ \\ ${ }^{1}$ Department of Community Medicine, University of Zimbabwe, Harare, Zimbabwe \\ ${ }^{2}$ Ministry of Health and Child Care, Harare, Zimbabwe \\ Email: ^tjuru@zimfetp.net, alicekdzvukamanja@gmail.com, tshuma.cremance@gmail.com, moblemu@gmail.com, \\ gombent@yahoo.com, mufutatshimanga@gmail.com
}

How to cite this paper: Dzvukamanja, A.K., Tshuma, C., Bangure, D., Mungati, M., Juru, T., Gombe, N.T. and Tshimanga, M. (2017) Evaluation of the Babies at Risk Surveillance System in Rushinga District, Mashonaland Central Province, Zimbabwe, 2015. Open Journal of Therapy and Rehabilitation, 5, 148-158.

https://doi.org/10.4236/ojtr.2017.54013

Received: April 19, 2017

Accepted: November 25, 2017

Published: November 28, 2017

Copyright $\odot 2017$ by authors and Scientific Research Publishing Inc. This work is licensed under the Creative Commons Attribution International License (CC BY 4.0).

http://creativecommons.org/licenses/by/4.0/

\begin{abstract}
Background: About $15 \%$ of world's population lives with some disability. Zimbabwe's prevalence of disability was at 7\% in 2013. ARSS is a paper-based system to monitor and detect neuro-developmental conditions and childhood disability early. Indicators for registering a baby into ARSS include: low Apgar score, low birth weight and birth asphyxia. Active case finding in Rushinga District in July 2015 identified nine cerebral palsy cases that were missed by the system out of 14 randomly chosen babies delivered at Chimhanda District Hospital. We evaluated the performance of the ARSS in Rushinga District. Methods: We evaluated the system using CDC guidelines for surveillance systems evaluation. All 12 health facilities in Rushinga were included. Health workers involved in ARSS were purposively recruited. Interviewer administered questionnaire, key informant interview guide, checklists and records review were used for data collection. Knowledge of participants on the system was assessed using five-point Likert scale. Data were analyzed using Epi Info 7. Results: Fifty-one participants were recruited for the study. Median years in service for all participants was $7\left(\mathrm{Q}_{1}=6 ; \mathrm{Q}_{3}=12\right)$. Average knowledge score was 3. Majority participants (82.4\%) were not trained on ARSS and cited lack of: knowledge, reporting guidelines, induction and focal persons as reasons for missing AR cases. Currently, ARSS is able to detect only $12.5 \%$ of cases. Prevalence of AR babies in Rushinga for period November 2014 to November 2015 was $21.1 \%$. Monthly cost of detecting and registering a case was USD \$52.46. Conclusions: ARSS was found to be useful, simple, acceptable and affordable, however was found to be unstable and not sensitive. Training of health workers particularly village health workers and integrating ARSS
\end{abstract}


with the DHIS2 could improve system performance. As a result of the evidence from this evaluation, it has been agreed to include ARSS data on the monthly return form (T5) beginning June 2016.

\section{Keywords}

At Risk Babies, Cerebral Palsy, Surveillance, Rushinga District

\section{Introduction}

Public health surveillance is the ongoing, systematic collection, analysis, interpretation of data, and the dissemination of information regarding a health related event for use in public health action to reduce morbidity and mortality and to improve health, [1]. Epidemiologic surveillance is conducted to describe and monitor a health event. Surveillance data are used for planning, implementing, and evaluating public health interventions and programs and to assess the effectiveness of programs. The evaluation of surveillance systems should include recommendations for improving quality and efficiency and should assess whether a system is meeting its objectives. Because surveillance systems vary widely in methodology, scope, and objectives, characteristics that are important to one system may be less important to another [1]. The WHO International Classification of Functioning, Disability and Health (ICF) describes disability as dysfunction at 1 or more of 3 levels: impairment of body structures (organs or limbs) or functions (physiologic or psychological), limitations in activities (execution of tasks or actions by the individual), and restriction of participation (involvement in life situations) [2].

An estimated 15\% of world's population lives with some form of disability [3], Zimbabwe's prevalence of disability is at 7\% according to the Key findings Report of the Zimbabwe Living Conditions among Persons with Disability Survey of 2013, which amounts to around 900,000 individuals based on a population of 13 million. About $25 \%$ of reported disability cases occurred before five years of age (MOHCC, 2013) [4]. It is against this background that the Ministry of Health and Child Care (MOHCC) through the Rehabilitation Department seeks to strengthen the At Risk Surveillance System (ARSS).

The ARSS is a paper-based public health surveillance system that was introduced in Zimbabwe in mid 1980s to detect and identify neuro-developmental conditions and disability in the first year of life particularly in the first 6 months for early intervention. It was meant to facilitate early identification of babies suffering from or suspected to have suffered brain damage and their prompt referral to rehabilitation services. The ARSS generates reliable estimates of the incidence of neuro-developmental conditions and disability, provides information on the spectrum of the conditions, and helps establish prevalence and patterns of the same. 
Indicators for a baby to be registered as an AR case include:

- Severe jaundice in the first week of life;

- Apgar score < 5 (both at 1 minute and at 5 mins after birth);

- Severe prematurity with birth weight $<1500$ g;

- Term baby with birth weight $<2500$ g;

- Neonatal Malaria/TB infection, or Meningitis;

- HIV/AIDS exposed;

- Neonatal convulsions;

- Term infant with delivery complications e.g. severe birth asphyxia, birth trauma;

- Floppy baby;

- Baby does not cry for more than 24 hours after birth;

- Baby does not suck for more than 24 hours after birth.

Flow of information in the AR surveillance system (refer to Figure 1) is such that Form A should be completed by maternity staff immediately after delivery at health facility to register an AR case who presents with any one of the indicators as entry point to the ARSS and an At Risk sticker is subsequently placed on the Road to health card of the baby to allow for follow up. Form A is then sent to the nearest Rehabilitation Department monthly. Form B is completed by Rehabilitation staff at district level after examination of AR cases. Copies of both

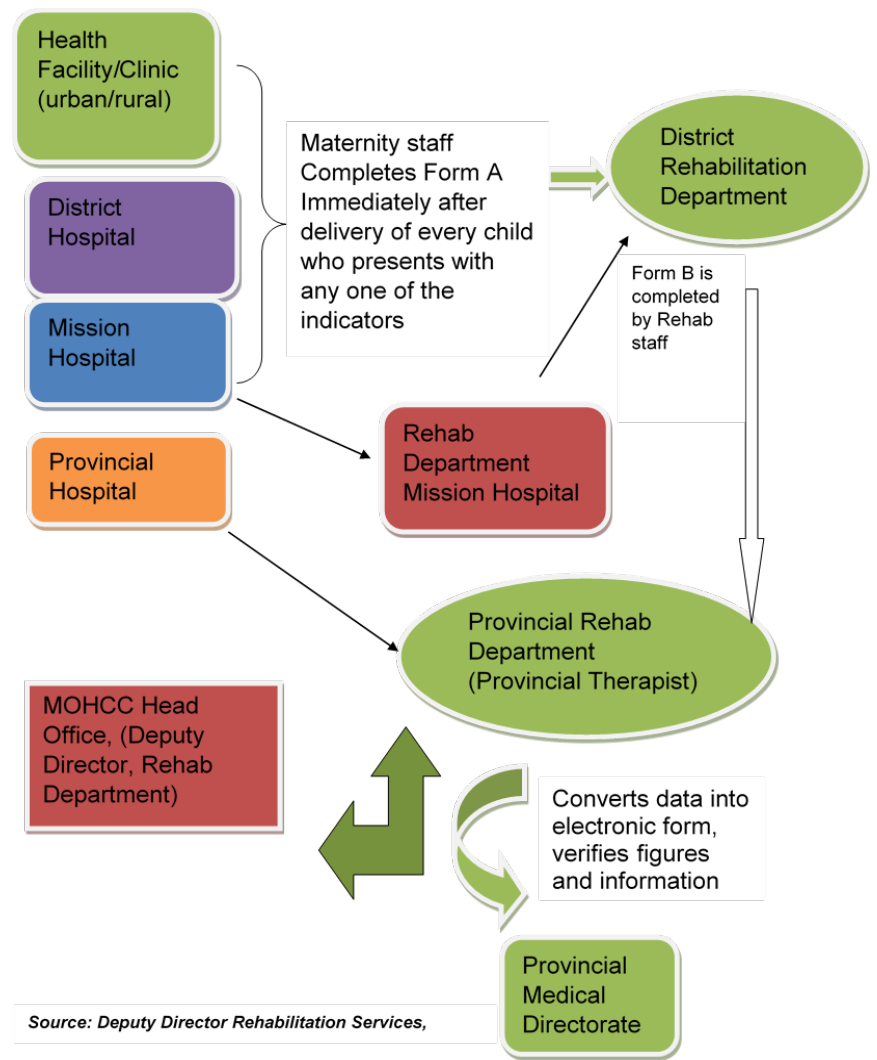

Figure 1. Flow of information in the At Risk Surveillance System (ARSS). 
forms are sent to province quarterly which then verifies figures and action. Data is converted to electronic form by the provincial therapist and submitted to Deputy Director Rehabilitation and Provincial Medical Director quarterly for analysis and action [5].

Active case finding in Rushinga District in July 2015 identified 9 cerebral palsy cases that were missed by the ARSS out of 14 randomly chosen babies delivered in the district through caesarean section. This suggested gaps at entry level in maternity and in follow up in family child health. We therefore evaluated the performance ARSS in Rushinga District, Mashonaland Central Province, 2015. Specifically we assessed the system attributes namely acceptability, simplicity, timeliness, stability, sensitivity as well as health worker knowledge and usefulness of the system. We also intended to establish the reasons for missing At Risk cases in Rushinga District 2015 and to cost the direct running of ARSS and to identify key areas for system strengthening.

\section{Methods}

We conducted a descriptive cross sectional study and surveillance system evaluation using updated CDC guidelines for surveillance system evaluation as a mixed method among health personnel involved in the ARSS. All 12 health facilities in Rushinga district were included. Health workers found on duty on the day of data collection were purposively recruited into the study. The Deputy Director Rehabilitation Services, Provincial therapist, District Medical Officer, District Nursing officer and Health Information Officer, Accountant, Lab Technician and Director Health Information, were purposively recruited into the study and interviewed as key informants. Using Dobson formula assuming that $29 \%$ of the health workers were knowledgeable about ARSS, and that it is similar to the case of AFP surveillance [6], with an absolute precision (d) of 5\%, 95\%CI and factoring a non response rate of $10 \%$. A minimum sample size of 49 was calculated. Pre-tested Interviewer administered questionnaires were used to interview health workers to determine reasons for missing AR cases, their knowledge and perception on the operations of the ARSS. Checklists were used to assess the system's stability and evidence of usefulness of the system. Delivery registers were reviewed to check on how many AR cases were captured by the surveillance system and how many were missed. All AR forms from November 2014 to November 2015 were reviewed to check for simplicity, data quality, completeness, acceptability, sensitivity and timeliness of the system. Data were cleaned for errors of entry and analysed using Epi info $7^{\mathrm{TM}}$. The software was used to calculate means, proportions and frequencies. Responses from the participants, were categorized by job designation where required. A double entry system was used to safe guard data quality. Qualitative data was analyzed thematically. This was done by quoting the verbal responses and grouping of responses with the same theme to bring out the key points. Permission to carry out study was obtained from provincial and district health authorities and from the 
MPH field office, University of Zimbabwe. Written informed consent was obtained from all study participants. Confidentiality was assured and maintained throughout the whole study. No information shall be linked to study participants in any way as anonymous numbers were assigned to each questionnaire and the questionnaire are being kept under lock and key.

\section{Results}

All 12 health facilities in Rushinga District were visited. The study successfully recruited 51 Health workers as study participants and 6 Health managers as key informants yielding a $104 \%$ response rate.

1) Demographic Characteristics of Study Participants, Rushinga District, Mashonaland Central Province, 2015

Of the 51 participants recruited, $73 \%(n=37)$ were female whilst $27 \%$ were male. The majority (76\%) of the participants were nursing staff. The median years in service of all participants was 7 years $\left(Q_{1}=6 ; Q_{3}=12\right)$, (Table 1$)$.

2) Knowledge of Health Workers on AR Surveillance System, Rushinga District, Mashonaland Central Province, 2015

Out of the 51 participants, 49 (96.1\%) knew the target age group for ARSS and only 25 (49\%) knew the number of forms to be filled. Thirty one (60.8\%) participants knew the indicators for registering an AR case and only six (11.8\%) knew the flow of information in the ARSS. Forty two (82.4\%) participants were not trained on AR surveillance and about 35 (70\%) said they need training on AR surveillance system. A 5 point Likert scale below was used to measure knowledge level. Those who had a correct answer average knowledge score of $40 \%$ or below $(\leq 40 \%)$ were awarded a score of 1 or 2 out of five and rated as having very poor to poor knowledge level, three (3) out of five knowledge level was awarded to those between $40 \%$ and $60 \%$ and rated as having fair knowledge level and those whose correct answer knowledge score was greater than $60 \%$ and $80 \%$ were awarded four and five $(\geq 4)$ was classified as having good to very good knowledge level. Overall, Knowledge on ARSS was generally rated as fair among health workers in Rushinga District.

Table 1. Demographic characteristics of study participants, Rushinga District, Mashonaland Central Province, 2015.

\begin{tabular}{cc}
\hline Characteristics & Frequency $\mathbf{n}(\%)$ \\
\hline Gender & $14(27.45)$ \\
Male & $37(72.55)$ \\
Female & $51(100)$ \\
Total & \\
Designation & $1(1.96)$ \\
Doctors & $39(76.47)$ \\
Nurses & $1(1.96)$ \\
Rehabilitation staff & $10(19.61)$ \\
Other & $7\left(\mathbf{Q}_{1}=6, \mathbf{Q}_{3}=12\right)$ \\
Median years in service (IQR) & \\
\hline
\end{tabular}


3) Reasons for missing At Risk cases in Rushinga District, 2015

Most participants cited lack of knowledge (75\%), unavailability of reporting guidelines, lack of induction the surveillance system and lack of focal persons as major reasons for missing AR cases. About a third cited not knowing who should report and only $23.5 \%$ indicated lack of staff as a reason for missing AR cases (Table 2).

\section{System Attributes}

1) ARSS Sensitivity, Rushinga District, Mashonaland Central Province, 2015

At the current status quo, i.e. with the current health staff knowledge level on ARSS, having no focal persons and with the current level of resources, the ARSS is able to detect only $12.5 \%$ of cases (Table 3 ).

The prevalence of AR babies in Rushinga district for the period November 2014 to November $2015=$ (Actual no. of cases/Total live births) $* 100 \%=$ $(568 / 2698) * 100=21.1 \%$.

2) Timeliness of the ARSS in Rushinga District, 2015

The ARSS was untimely in that most of the time cases took long or they were never reported. Overall, most cases 497 (87.5\%) were missed. AR cases were missed at birth which caused the first delay of registration whilst other cases were still being missed 6 months after birth during immunizations and growth monitoring when they could have been picked up by the system.

3) Acceptability of the ARSS in Rushinga District, Mashonaland Central Province, 2015

In terms of ARSS acceptability level, $80.5 \%$ of participants felt that it was their duty to complete the AR forms and $95.8 \%$ participants were willing to continue participating in the ARSS. Thus based on the subjective assessment gathered

Table 2. Reasons for missing At Risk cases in Rushinga District, 2015.

\begin{tabular}{cc}
\hline Reason & Frequency $\mathbf{n}(\%)$ \\
\hline No induction on the surveillance system & $30(58.3)$ \\
Do not know who should report & $14(27.5)$ \\
lack of knowledge & $38(74.5)$ \\
Lack of staff & $12(23.5)$ \\
No reporting guidelines & $31(60.8)$ \\
Unavailability of reporting forms & $20(39.2)$ \\
No focal persons & $24(47.1)$ \\
\hline
\end{tabular}

Table 3. At Risk Surveillance System's Sensitivity, Rushinga District, Mashonaland Central Province, 2015.

\begin{tabular}{ccccc}
\hline Year & Total live births & $\begin{array}{c}\text { No. of cases } \\
\text { detected }\end{array}$ & $\begin{array}{c}\text { Actual } \\
\text { cases experienced }\end{array}$ & $\begin{array}{c}\% \\
\text { Sensitivity }\end{array}$ \\
\hline $\begin{array}{c}\text { November } \\
\text { 2014 to November 2015 }\end{array}$ & 2698 & 71 & 568 & $12.5 \%$ \\
\hline
\end{tabular}


from the interview, on average ARSS is $88 \%$ acceptable to health workers in Rushinga District. However, those who felt that it was not their duty to complete AR forms indicated that it was Rehabilitation Staff and qualified nursing staff who should complete the forms since they know how to do the assessments and are more likely to detect the cases first. The acceptability of the ARSS was also assessed objectively by considering its timeliness which was poor $(87.5 \%)$ of the time and the completeness AR forms completed. Nine (75\%) of health facilities had completely filled in forms (improvised counter books) whilst the rest sometimes omitted the details of the mother. These details are particularly important to allow for follow of identified cases. The ARSS acceptability was therefore rated as fair.

4) Simplicity of the ARSS, Rushinga District, Mashonaland Central Province, 2015

Out of the 51 participants only $15(29.4 \%)$ participants had ever identified an AR case. Reported average time taken to complete AR forms was 10 minutes. However whilst being timed, participants took an average of 5 - 7 minutes to complete the AR forms whilst the researcher took about 3 minutes to complete the AR forms. Ten (19.6\%) participants reported that the forms were easy to complete, but however, 35 (68.6\%) of participants indicated that they needed training on completing the questionnaires. In addition, 23 (45.1\%) participants indicated that they needed specific training on the ARSS in general i.e. its case detection indicators, physical examination of cases and case reporting with the hope that it further simplifies the ARSS.

5) Stability of the ARSS, Rushinga District, Mashonaland Central Province, 2015

Twenty three (45\%) of participants reported that they had AR case definitions in their health facilities and five out of 12 (41.7\%) health facilities had the AR case definition displayed. However, there was no formal IEC case definition chart displayed in these health facilities but improvised printed A4 bond papers or manila charts written with mighty markers. All 12 facilities had at least an improvised AR form recording by use of a counter book or improvised forms that captured name of child, address and reason for registering the AR case. (55\%) reported that they used a cell phone to report an AR case. 6\% indicated that they use email to send AR information to the next level. Only 12 (24\%) participants reported that they once had access to health facility transport to follow up or refer AR cases. Other means of communication used were radio communication, EPI vehicle, motor cycle, bicycle, public transport or walking to the next level when conducting ARSS.

6) Usefulness of ARSS, Rushinga District, Mashonaland Central Province, 2015

Overall, 43 (97.7\%) perceived ARSS as useful. Forty one (80.4\%) reported that data was used in some way at their level whilst $30(58.8 \%)$ said data collected is analysed. 19 (40.4\%) said they held meetings and only Chimhanda Hospital had 
a hard copy of minutes available. Those who did not make any decision based on ARSS data attributed it to lack of a focal person. Others cited issues of lack of coordinated meetings and lack of feedback. Usefulness was evidenced by a Rehabilitation village held at the hospital and the efforts made by the Rehabilitation department to move around all clinics explaining the importance of collecting ARSS data. However, 2 (3.96\%) participants felt that the system was not useful since no feedback was being given and little was being done to help the AR cases identified due to lack of funding for Rehabilitation programs. Usefulness was therefore overall, rated using a 5 point Likert scale and on average ARSS was rated as somewhat useful.

7) Cost of Running the ARSS, Rushinga District, Mashonaland Central Province, 2015

Cost of running the ARSS were estimated using information gathered from a key informant interview-the Accountant who has had experience with running processes of other surveillance systems and programs. Usually IEC materials are provided as hard copies by funding partners. The total estimated monthly cost of running the ARSS in Rushinga District in 2015 was at USD\$2517.90 (See Table 4).

8) Suggested areas for system improvement

Most participants, 44 (86.3\%) suggested training more health workers on the ARSS to help improve its performance. Over half 27 (53\%) and about a third of participants (29.4\%) suggested that introduction of focal persons and provision

Table 4. Cost of Running the ARSS, Rushinga District, Mashonaland Central Province, 2015.

\begin{tabular}{|c|c|c|}
\hline Item & Quantity & $\begin{array}{c}\text { Estimated cost } \\
\text { per month (USD) }\end{array}$ \\
\hline $\begin{array}{l}\text { 1. Vehicle service and } \\
\text { maintenance }\end{array}$ & Per month & $\$ 500$ \\
\hline \multicolumn{3}{|l|}{ 2. Fuel (Petrol and Diesel) } \\
\hline -program & 320 Litres @ \$1.25/1 & $\$ 400$ \\
\hline -support and supervision & 120 Litres@ @ $1.25 / 1$ & $\$ 150$ \\
\hline 3. Airtime & $\$ 20 * 12$ facilities & $\$ 240$ \\
\hline $\begin{array}{l}\text { 4. Stationary including } \\
\text { cartridge }\end{array}$ & $\$ 100$ & $\$ 100$ \\
\hline \multirow[t]{2}{*}{ 5. IEC material-ready printed } & Banner, brochures \& pamphlets & - \\
\hline & Per month & $\$ 960$ \\
\hline 6. Allowances & $=$ Once a week $* 4$ people & $\$ 140$ \\
\hline $\begin{array}{c}\text { Support \& supervision } \\
\text { Acquittals/Acscounts team }\end{array}$ & $\begin{array}{c}\text { (Rehab, DNO, driver and } 1 \text { focal nurse at each } \\
\text { RHC)@ } \$ 40^{*} 3 \text { days to cover whole district } \\
5 \text { days per month @ } \$ 20 \text { plus driver } \\
\text { ( } 2 \text { days) @ } \$ 20\end{array}$ & $\$ 2490$ \\
\hline $\begin{array}{l}\text { Bank account charges-standard } \\
\text { Chartered account }\end{array}$ & $1.12 \%$ of withdrawals & $\$ 27.90$ \\
\hline 7. Total costs & - & $\$ 2517.90$ \\
\hline
\end{tabular}


of adequate stationary can help improve the system. Nine (18\%) of the participants suggested that providing more health staff can improve the ARSS. Other suggested ways of improving the system included incorporating ARSS on the T5 and on DHIS2, involvement of Village Health Workers (VHWs) and EHTs, improving internet coverage, provision of IEC material (case definition charts, posters and reporting guidelines) and providing financial support for active case finding and allowances.

\section{Discussion}

Health workers should be knowledgeable about the surveillance system so that they are able to identify AR cases and register them. This study found that majority of health workers were not trained on AR surveillance which may be affecting ARSS performance. No direct literature was found on ARSS but however, a local study by Chirundu et al. (2005) on AFP Surveillance highlighted that lack of knowledge resulted in the missing of some AFP cases in Mberengwa and Shurugwi districts [7]. If health workers perceive the system to be difficult despite it being simple, they may avoid reporting cases thereby increasing the number of missed cases depriving the community of a needed service. Simplicity was being affected by previous experience of completing an AR form such that 35 (69\%) participants with no prior experience with the forms said that they needed training in order to be able to complete and familiarise with the forms. Moreover, despite the system being acceptable since about $96 \%$ were willing to continue participating in ARSS, the majority of the health workers stated that they needed training on ARSS indicators and background and on how to complete the forms. This was consistent with findings reported by Pomerai et al. in Bikita district where lack of were training on AFP surveillance was attributed to high staff turnover between 2007 and 2009. Subsequently, this study found that ARSS is not sensitive which is consistent with findings by Dube et al. in Mpumalanga, South Africa, 2009, who postulated that the AFP surveillance system was not sensitive. [8] Missing AR cases in a district may result in an increase in the number of preventable childhood neuro-developmental conditions and disability.

\section{Conclusion}

Knowledge among health workers in the district was fair. Possible reasons for missing AR cases were lack of knowledge among health workers, lack of focal persons, no reporting guidelines and reporting forms, lack of induction on the system, lack of integration with other surveillance systems and inadequate stationary and resources for community mobilization and awareness campaigns. The AR surveillance system was therefore found to be useful, simple, acceptable, not timely, unstable and not sensitive.

\section{Ethics Approval and Consent to Participate}

Ethical Approval was granted by Rushinga Institutional Review Board. 


\section{Consent for Publication}

All participants signed consent for participation and publication.

\section{Availability of Data and Materials}

All data bases can be made available upon request to the corresponding author.

\section{Competing Interests}

The authors declare that they have no competing interests both financially and non-financial.

\section{Funding}

This study was supported by the Ministry of Health and Child Care, Zimbabwe.

\section{Author Contributions}

AKD and TC: conception, design, acquisition, data collection, analysis and interpretation of data and drafting the manuscript. MM, NTG, in data analysis and interpretation; MT, TJ had oversight of all stages of the research and critically reviewed the final draft for important intellectual content. All authors read and approved the final manuscript.

\section{Acknowledgements}

I would like to express my sincere gratitude to the staff in Rushing a district for their support. Special thanks go to MPH field office for all the support they rendered. We would also like to express our profound gratitude to UNICEF and Centres for Disease Control and Prevention (CDC) Zimbabwe for funding and technical input. Many thanks go to all participants for their consent to participate in the study. Last, but not least, I would like to thank my family for social support throughout the project.

\section{References}

[1] CDC (2001) Updated Guidelines for Evaluating Public Health Surveillance System. Recommendations from the Guidelines Working Group. MMWR, 50(RR-13), 1-35.

[2] WHO (2015) International Classification of Disabilities (ICF). https://www.cdc.gov/nchs/data/icd/icfoverview_finalforwho10sept.pdf

[3] WHO (2011) World Report on Disability. http://www.who.int/disabilities/world_report/2011/report.pdf

[4] MOHCC (2013) Living Conditions among Persons with Disability Survey. Key Findings Report, 1-62.

[5] MOHCC (2012) Rehabilitation Manual, 2012. 1-88.

[6] Pomerai, K.W. (2014) Evaluation of the Acute Flaccid Paralysis (AFP) Surveillance System in Bikita District, Masvingo Province, 2010. BMC Research Notes, 7, 252. https://doi.org/10.1186/1756-0500-7-252

[7] Beers, M.H. and Berkow, R. (1999) The Merck Manual of Diagnosis and Therapy. 
17th Edition, Merck Research Laboratories, Whitehouse Station, NJ.

[8] Dube, N., Tint, K. and Gouws, A. (2011) Evaluation of the Acute Flaccid Paralysis Surveillance System, Mpumalanga Province, South Africa, 2005-2009.

\title{
List of Abbreviations
}

\author{
AR: At Risk \\ CDC: Centre for Disease Control \\ CNS: Central Nervous System \\ DHE: District Health Executive \\ DMO: District Medical Officer \\ DNO: District Nursing Officer
}

EPI: Expanded Program for Immunisation

ICF: International Classification of Functioning, Disability and Health

MDGs: Millennium Development Goals

MOHCC: Ministry of Health and Child Care

PHE: Provincial Health Executive

PMD: Provincial Medical Directorate

PLWD: People Living With Disabilities

UNCRC: United Nations Convention on the Rights of the Child

UNCRPD: United Nations Convention on the Rights of Persons with Disabilities UNICEF: United Nations Children's Fund

WHO: World Health Organization 